\title{
Factors of Neonatal Morbidity at the Provincial Hospital Center of Missour
}

\author{
Loubna Doukkali' ${ }^{1}$ Nada Bennani Mechita2 ${ }^{2}$, Laila Lahlou ${ }^{2}$, Fatima Zahra laamiri' ${ }^{1}$, \\ Mouna Habibi' ${ }^{1}$ Amina Barkat ${ }^{1}$ \\ ${ }^{1}$ Faculty of Medicine and Pharmacy of Rabat, Research Team in Maternal and Child Health and Nutrition, \\ Mohammed V University, Rabat, Morocco \\ ${ }^{2}$ Laboratory of Biostatistics and Clinical Research and Epidemiology, Faculty of Medicine and Pharmacy, Rabat, \\ Morocco \\ Email: barakatamina@hotmail.fr, I_doukkali@yahoo.fr, nadaben7@gmail.com,drlailalahlou@ymail.com, \\ fatilamir1970@yahoo.fr, habibimouna@gmail.com
}

Received 23 March 2016; accepted 16 May 2016; published 19 May 2016

Copyright (C) 2016 by authors and Scientific Research Publishing Inc.

This work is licensed under the Creative Commons Attribution International License (CC BY). http://creativecommons.org/licenses/by/4.0/

cC) (7) Open Access

\begin{abstract}
Background: Although neonatal mortality decreases in different regions of the world, it is still a major problem in developing countries and particularly in Morocco. Purpose: The aims of this study are to examine the characteristics of pregnant women in the hospital center in the urban commune of Missour as well as the morphological data of the newborn and identify the risk factors implicated in neonatal morbidity. Materials and Methods: A retrospective study of collected data from records of women who gave birth in the Maternity of Missour during 2012. As well as a prospective study conducted at the maternity in 2013. Results: A total of 1108 women were included in this retrospective survey, of which $45 \%$ come from areas located far from the hospital center of the province and sometimes the access is tough in winter. Only $55.1 \%$ of pregnancy was followed. Among 1121 births, 49 babies (4.3\%) showed a problematic birth situation: 31 (2.7\%) newborns were hospitalized in pediatrics, of which 14 are premature. Neonatal mortality rate is $0.6 \%$ that is to say 7 early deaths. The risk factors associated to neonatal morbidity are gestational age and weight birth (in $50 \%$ of the cases, $85.7 \%$ of deaths are premature infants less than $1500 \mathrm{~g}$ ). $14(1.2 \%)$ were referred and $11(0.9 \%)$ malformed were noticed. The prospective study states that among the 194 women analyzed, $89.7 \%$ are housewives. $89.1 \%$ have no medical coverage and $\mathbf{2 5 . 4 \%}$ are illiterate. Only $\mathbf{2 9 . 2 \%}$ benefit from a blood sample during pregnancy and $50 \%$ benefit from regular ultrasound follow-up. Conclusion: Mortality and neonatal morbidity constitute a public health priority in Morocco. Our work insists on the interest of an organized support of the newborn from the community to the different levels of the health pyramid.
\end{abstract}




\section{Keywords}

\section{Precariousness, Perinatal Risk, Regionalization, Community Actions}

\section{Introduction}

The neonatal mortality means the death of children born alive and dead between 0 and 27 days. If almost all the continent is severely affected, the situation in North Africa, particularly in Morocco has known a clear evolution. Several programs have been established like the monitoring system of maternal deaths in 2008, with the construction of at least one service of intensive neonatal unit by region at the national level. The neonatal mortality rate according to recent official data in 2011 of the Health Ministry is evaluated to 18.8 per thousand with a decreasing of 30 percent. However it remains high in comparison to the European Union countries. But we still note an increase of this downward trend in the last five years [1].

However, neonatal mortality during the first 4 weeks of life is 14 times higher in the under-developed countries and UNICEF states that 4 million newborns die following a disease or other preventable causes. Moreover, these deaths represent 40 percent of the total of children mortality under 5 years old according to the UN organization [2].

In Missour, there is little epidemiological information reliable on morbidity and neonatal mortality and the factors associate with the community level. The objective of our study was to assess the importance of the situations of precariousness among pregnant women and their consequences on the state of health of newborn, to compare the provincial data at the national level and to determine the principal causes of death.

\section{Patients and Methods}

\subsection{Study Place}

We conducted our study at the maternity of the provincial hospital center of Missour which is a maternity type II with a number of annual births assessed to 1200 . This provincial hospital Center is a subdivision that mostly receives patients from the rural area of the Moroccan region of Fez-Boulemane, and which covers an area of $14.600 \mathrm{Km}^{2}$ with a population estimated to 202.000 inhabitants and of which 23.250 (namely 11.5\%) are originating in commons with difficult access in winters. In order to respond to the objective assigned by our work, two studies have been carried out: the first one is a retrospective study and the second is a prospective one.

\subsection{The First Study}

\subsubsection{Patients}

Inclusion criteria: this is a retrospective study of Moroccan women who gave birth in the Maternity of Missour current 2012 regardless of their gestity and parity and the fate of their pregnancy. The limits of our work were mainly related through exclusively hospital recruitment.

Exemption criteria: we excluded from the study all women with interruptions of pregnancy and in-utero fetal death.

\subsubsection{Data Collection}

The main socio-demographic data, maternal obstetric and neonatal data were collected from records of the maternity province. For each newborn, an information sheet was filled by doctors and midwives that analyzes the characteristics of the mother (origin, maternal age, gestity, parity, term and monitoring of pregnancy and infectious anamnesis), the characteristics of delivery (place of birth, mode of delivery) and child characteristics (age, sex, birth weight, Apgar score at birth).

In addition to that, a part of the study focused on the causes of neonatal deaths origin and causes of maternal and obstetric and the various post-natal complications observed.

\subsubsection{Definition of Terms}

A rural area with difficult access corresponds to an enclosed sanitary health area due to the lack or dilapidated 
road network, generally badly served by modern conveniences and whose health services are poorly provided by qualified professionals. It concerns any area located between 80 and $400 \mathrm{~km}$ away from a first referral hospital [3].

In our context, an area with difficult access is considered from a distance of 8 - $10 \mathrm{~km}$ away from a sanitary structure with difficult access.

A pregnancy is stated monitored if the woman in labor benefits from 4 prenatal consultations, one each quarter and one before delivery.

The immediate fate defined by the analysis of the evolution of newborns according to WHO (World Health Organization) and according to national recommendations in the 24 hours that followed their delivery.

A healthy newborn was defined as any birth with good adaptation to extra- uterine life (Apgar $>7$ ) and bears no clinically detectable malformation.

In the absence of $\mathrm{pH}$ measurement as call sign together with biological and electroencephalographic arguments, confirmation of neonatal asphyxia in our context is difficult and clinical criteria are very important (pathologic foetal heartbeat and Apgar score $<3$ in 5 minutes).

Neonatal infection was selected according to criteria in our national best practice recommendations [4]: suspision of chorioamnionitis, maternal temperature $38 \mathrm{C}$, spontaneous prematurity $<37$ weeks of amenorrhea (SA), rupture of membranes 12 hours, maternal colonization with Group B Streptococcus without antibiotic prophylaxis, changes in foetal heartbeat, meconium amniotic fluid, symptomatic newborn (hypo or hyperthermia, respiratory distress, respiratory pause, gray complexion, tachycardia, bradycardia, hypotension, blurred tone, disturbance of consciousness, eating disorders [1]-[5]. None of PCT (Procalcitonin) assay in the cord was made [6]-[8].

Early neonatal death is a death occurring within 24 hours of delivery.

\subsection{The Second Study}

The aims of this prospective study is to analyze the others sociodemographic variables of parturient associated with perinatal complications that have not been used in the retrospective study in order to establish adapted social preventive measures.

\subsubsection{Patients}

Inclusion criteria: this prospective study involved all pregnant women, regardless of gestity and parity, who have consulted the maternity of Missour the first 3 months of 2013 in working hours and days during work hours.

Exemption criteria: no woman has been excluded.

\subsubsection{Data Collection}

The information was gathered from a baseline questionnaire that has been evaluated and tested by our research team, and was intended for the midwives to explore women's precarious situations. Women in labor were asked about demographic and socio-economic data (mother's age, marital status, work, medical coverage, school level, father's age, school level of the father, father's work). Information on the monitoring of the pregnancy and the existence of an associated pathology were also collected. The questionnaire also informed on the existence or absence of a consanguinity, a chronic pathology during pregnancy, the biological monitoring and ultrasound imaging during the pregnancy.

\subsubsection{Definition of Terms}

- Family precarious defined through the four fields classically described in the literature: personal insecurity for lack of psychological resources, economic insecurity by funding shortages, social insecurity related to impairments of social ties and medical precariousness [9] [10].

- Medical coverage:

$\checkmark$ RAMED: the regime of medical assistance which has been established in 2011 and which covers poor people (informal workers, jobless people...).

$\checkmark$ CHI: the compulsory health insurance created in 2002 for employees. 


\subsection{Statistical Analysis}

Statistical studies have been developed by the team of the biostatistics department (laboratory of Epidemiology Clinical Research) at the Faculty of Medicine and Pharmacy of Rabat. Epidemiological parameters collected on survey forms were entered and analyzed using Statistical Package for Social Sciences (SPSS) software Version 13.0 then evaluated initially by a statistical analysis using the Pearson chi2 test. The results are expressed as numbers and percentages. When the conditions of application of the Pearson chi2 test were not valid, we used Fisher's exact test.

The degree of statistical significance was retained for a $\mathrm{p}<0.05$.

\subsection{Ethical Considerations}

Respect for the anonymity and confidentiality of information was strictly adhered to. Informed consent was signed before the inclusion of women in the study.

\section{Results}

\subsection{The First Study}

\subsubsection{Sociodemographic and Medical Characteristics of Pregnant Women (Table 1)}

1108 Pregnant women in precarious situations were studied, 45\% (494 cases) come from areas located more than $50 \mathrm{~km}$ of the provincial hospital center of Missour. 61.7\% (674 cases) were on average younger (20 to 30). Multiparous mothers 52.3\% (574 cases) were more numerous. Note that only 55.1\% (593 cases) were followed. 85.9\% (947 cases) gave birth by vaginal delivery.

\begin{tabular}{lc} 
Table 1. Sociodemographic and medical characteristics of pregnant women ${ }^{\mathrm{a}}$. \\
\hline Characteristics & Pregnant women $\mathrm{n}=1108$ \\
\hline Mother's origin & \\
$<50 \mathrm{~km}$ & $604(55 \%)$ \\
$>50 \mathrm{~km}$ & $494(45 \%)$ \\
Age group (years) & \\
$<20$ & $128(11.7 \%)$ \\
20 to 30 & $674(61.7 \%)$ \\
31 to 40 & $270(24.7 \%)$ \\
$>40$ & $21(1.9 \%)$ \\
Gestity-parity & \\
Primiparous & $524(47.7 \%)$ \\
Multiparous & $574(52.3 \%)$ \\
Monitoring of pregnancy & \\
Yes & $593(55.1 \%)$ \\
Non & $484(44.9 \%)$ \\
Term pregnancy(weeks of amenorrhea) & \\
$<37$ & $34(3.1 \%)$ \\
37 to 41 & $1035(94.7 \%)$ \\
$>41$ & $24(2.2 \%)$ \\
Mode of delivery & \\
vaginal delivery & \\
Caesarean delivery & $947(85.9 \%)$ \\
Infectious anamnesis & $156(14.1 \%)$ \\
Positive & \\
Negative & $328(30.1 \%)$ \\
Premature birth & $761(69.9 \%)$ \\
Malformed newborn & \\
Newborn referred & $37(3.4 \%)$ \\
Newborn hospitalized in Pediatrics & $11(0.9 \%)$ \\
\hline & $14(1.2 \%)$ \\
\hline & $31(2.7 \%)$ \\
\hline & $7(0.6 \%)$ \\
\hline
\end{tabular}

${ }^{\mathrm{a}}$ Values are expressed as count and percentage. 


\subsubsection{Health of Newborn Children}

1121 newborns were analyzed with 3.4\% (37 cases) were premature infants. 50.6\% (568 cases) were female sex. Only $4.1 \%$ (46 cases) had a low birth weight and $88.31 \%$ (990 cases) had a normal birth weight. 13 twin pregnancies were recorded (Table 2).

49 newborns (4.3\%) had neonatal morbidities to the delivery room whose 31 (2.7\%) newborns were hospitalized pediatric (Table 1). 55\% for neonatal infection, 22\% for neonatal distress, $10 \%$ for hyaline membrane disease and $3 \%$ of congenital malformation. Among 31 newborns 14 were premature infants and $10 \%$ very preterm birth.

The neonatal mortality rate was estimated at $0.6 \%$ corresponding to6 premature infants died within 48 hours of hospitalization and a newborn at term died at the maternity hospital. Mortality was higher in the group of preterm low birth weight less than 1500 grams corresponding to $50 \%$ ( 3 cases) and is $83.3 \%$ ( 5 cases) for a term less than 33 weeks gestation. The causes of death are dominated by hyaline membrane disease $28.5 \%$ (2 cases), neonatal infection $28.5 \%$ ( 2 cases) and neonatal asphyxia $43 \%$ ( 3 cases).

14 (1.2\%) were referred to the Fez University Hospital Center for emergency neonatal due to lack of resources at the provincial hospital and among these newborns transferred $50 \%$ had a congenital malformation, $36 \%$ neonatal asphyxia, $7 \%$ neonatal infection and 7\%, neonatal respiratory distress from undetermined causes.

11 congenital malformations corresponding to $0.9 \%$ were noted: $27 \%$ of dysmorphic syndrome, $19 \%$ ompha-

Table 2. Characteristics of the newborns complicated and healthy in univariate analysis $(\mathrm{N}=1121$ newborns in total of which 49 complicated).

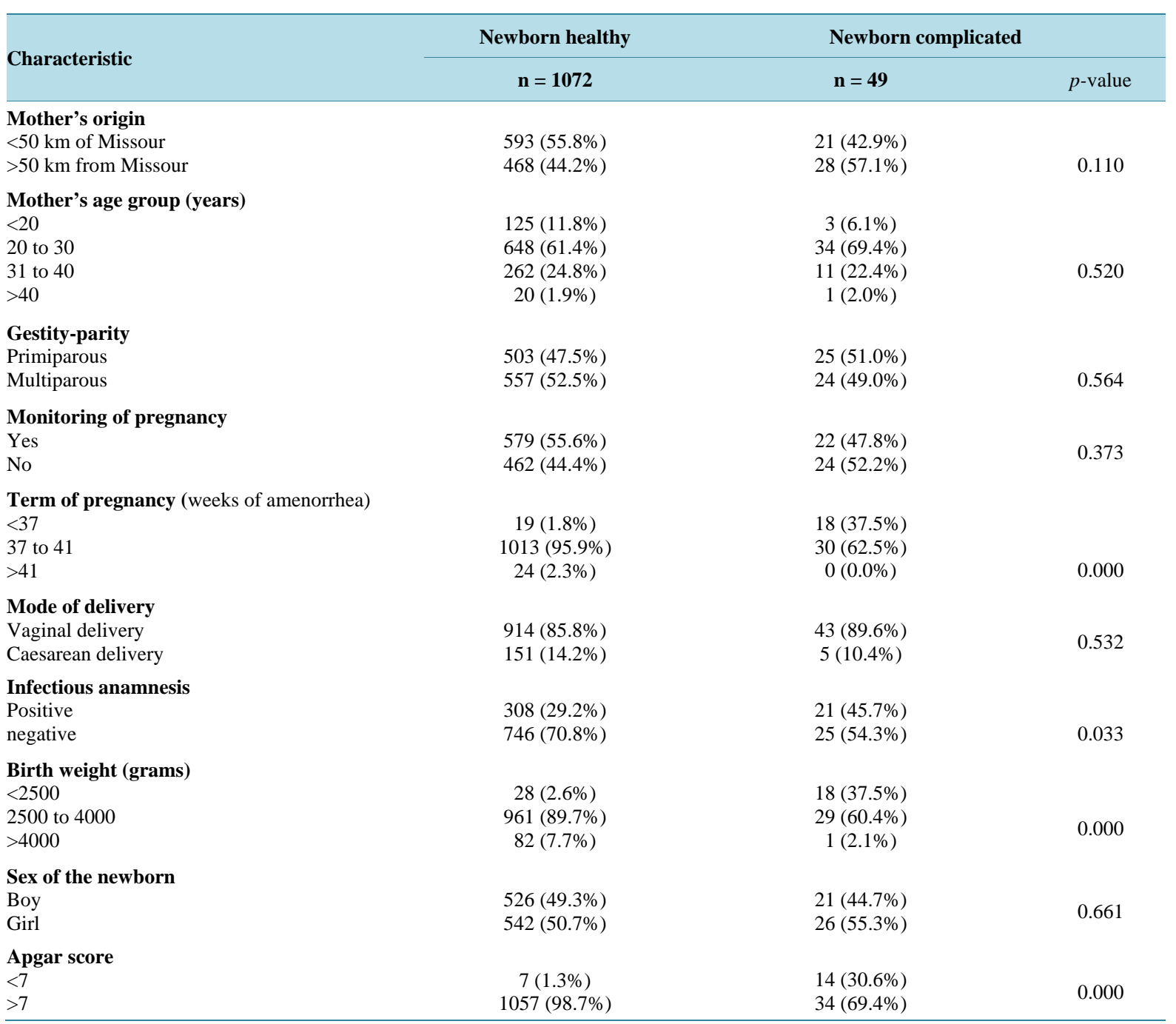


locele, $18 \%$ orthopedic malformations, $9 \%$ urologic malformations, $9 \%$ facial malformation, and $9 \%$ esophageal atresia.

\subsubsection{Factors of Neonatal Morbidity (Table 2)}

Table 2 compares the major medical characteristics of healthy newborns and those complicated to define the major neonatal morbidity factors.

Note that complicated newborns who are small for gestational age with low birth weight was more important than healthy $37.5 \%$ vs. $2.6 \%(\mathrm{p}=0.000)$.

Complicated newborns were more frequently complicated an Apgar score $<7$ Apgar score five minutes of life $30.6 \%$ vs $1.3 \%$ healthy newborns $(\mathrm{p}=0.000)$.

Infectious positive anamnesis history was more common in complicated newborns $45.7 \%$ versus those who are healthy $29.2 \%(\mathrm{p}=0.033)$.

Complications regarding the newborn are strongly related to preterm birth: $37.5 \%$ premature complicated newborns $1.8 \%$ vs healthy newborns (0000).

No significant differences were found in terms of mother's origin, mother' age, gestity-parity, monitoring of pregnancy and mode of delivery.

There is no difference between the two newborns groups regarding sex $(\mathrm{p}=0.661)$.

\subsection{The Second Study}

194 parturients were studied in the Maternity of Missour for which other sociodemographic parameters have been analyzed. $89.3 \%$ are house wives. $0.5 \%$ are beneficiaries of the RAMED, $10.8 \%$ of the compulsory health insurance and $89.1 \%$ have no medical coverage. $49.2 \%$ are from level secondary school, $13.8 \%$ of primary school, $11.6 \%$ of university and $25.4 \%$ are illiterate. $79 \%$ of the fathers have a paid work. $17.7 \%$ are from the primary level, $38.2 \%$ of the secondary level, $24.2 \%$ of university and $19.9 \%$ are illiterate (Table 3).

In $94.3 \%$ (184 cases), no pathology has been reported during pregnancy and only 3 cases of high blood pressure have been noted. The taking of plants was found in 2\% (4 cases) of women. Only 29.2\% (57 cases) have benefited from a sampling of blood during the pregnancy and $50 \%$ of an ultrasound monitoring quarterly.

\section{Discussion}

Neonatal mortality is 10 to 15 times higher in developing countries than it is in developed ones [11]. Out of the 130 million children who are born annually in the world 4 million die during the first 4 weeks of their life especially in countries with low resources [12] [13]. The biggest part of this mortality occurs in the first day of life, which is the case for our deaths [2].

By subscribing to the Millennium Development Goals, Morocco has started to reduce the under-five mortality rate by two thirds in 2015 in order to move from 76 to 25 deaths per thousand live births [3]. However, the Ministry of Health has set up a plan that aims to accelerate the reduction of maternal and child mortality to improve the quality of care for women in labor who are facing problems of access to obstetric care. Indeed, great inequalities between urban/rural areas, between regions and socio-economic backgrounds persist and our birth's structure suffers from a lack of qualified staff and appropriate equipment. The reduction of infant and child mortality which is due to the neonatal period in more than $60 \%$ of cases has increased from 47 to 36 deaths per thousand live births (2009/10 national survey) [1] but it remains slow.

The studied population seems representative of an urban district with a predominantly rural subdivision with limited access to early neonatal care including modern technology. The analysis of our results shows that the main factors of neonatal morbidity are preterm birth, low birth weight, the neonatal infection and neonatal distress (Table 2).

Our results confirm the importance of economic determinants [14], especially joblessness and low income of the parents making the continuity of healthcare impossible due to financial difficulties (Table 1). Many women have pointed out their troubles to reach the maternity because of the long distance from their homes but also the travel expenses engaged [15] which interrupt a regular monitoring of pregnancy (Table 3). Poor prenatal care quality noticed among women in labor of the 2nd study is a promoting factor of this morbidity [16].

Also, the marginalization and the ignorance sometimes generate the leak of institutions, making the medical follow-up with the general practitioner difficult [17]. One-third of our women in labor are however illiterate or 
Table 3. Sociodemographic and epidemiological characteristics of pregnant women ${ }^{\mathrm{a}}$.

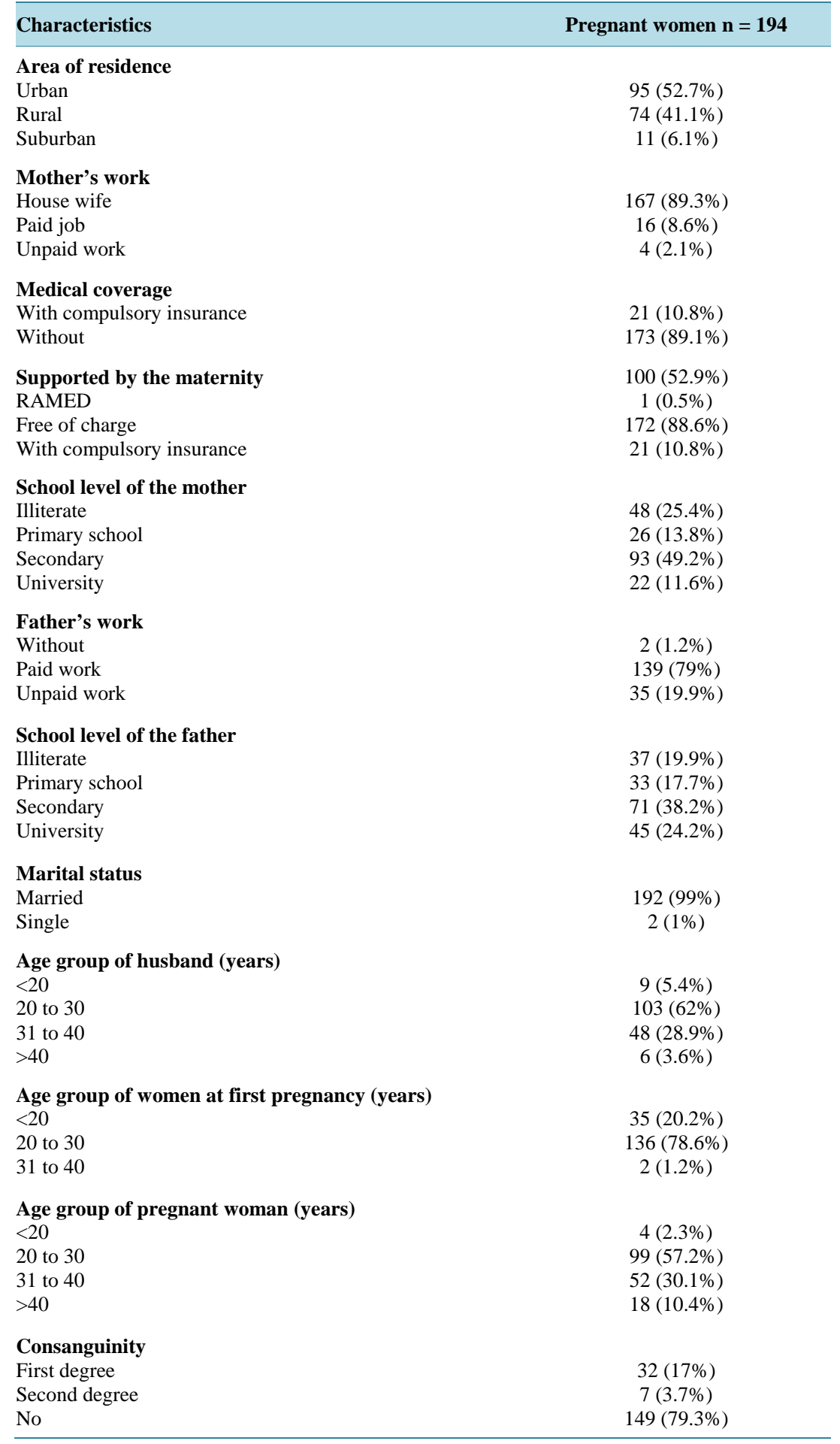

${ }^{a}$ Values are expressed as count and percentage. RAMED: regime of medical assistance which covers the poor people.

have a maximum of secondary school level (Table 3). Nevertheless, a late screening of certain maternal conditions and the use primarily of traditional healers services probably unacknowledged by our women in labor because of their cultural penchants, are all elements causing neonatal complications including malformations [18] 
(Table 1).

Moreover, the teratogenic effect of drugs or certain diseases wasn't proved in our study. In literature, the malformations of the central nervous system and the neural tube are responsible of a large part of neonatal morbidity different from those involved in our study showing the impact of environmental and ethnic variations that determine certain risk factors besides the prophylaxis with folic acid systematically introduced by the Ministry of Health for women in labor in Morocco [19]-[21].

The fight against neonatal mortality could be exempted by essential care for maternal and neonatal health through better neonatal care, the implementation of regional perinatal networks responsible for hospital inter transfers as well as continuous training of teams in the field.

Prenatal diagnosis of certain neonatal complications enables preparation of the birth in a proper neonatology center.

The neonatal transfer must ensure the five chains of survival of the newborn from the maternity to the reception service: the warm chain, the chain of oxygen, the chain of hemodynamic, hydration and asepsis [22].

The interlocutor (pediatrician, midwife or obstetrician) should inform about the complete situation of the newborn. Similarly, the recipient doctor must handle correctly the child waiting for the transport team [23].

These are the simple things at the base but essential. Unfortunately, they are not always available in some areas of the kingdom as it is the case of Missour maternity which is a maternity type II under-equipped with modern and sanitary technology. Indeed, we noticed a lack of proper technical equipment of neonatal reanimation and nursing is not always worthy of an intensive care unit; the only neonatal respiratory support available is the oxygen therapy.

The transfer to a first class service is sometimes impossible due to the lack of space in the reference center or too risky taking into consideration the conditions of the newborn and the precarious means of transport (only one poorly equipped ambulance and not always available). Certain parents refuse the hospitalization of those newborn because of their inability to pay.

Similarly, deliveries structures are not all at the optimum of their functionality for several reasons, including those related to the lack of equipment and qualified staff (one pediatrician for the whole Province as well as two gynecologists and one midwife for birthing home).

These epidemiological data highlight the importance of precocious neonatal care to reduce hypoxia and hypothermia and of a qualified neonatal reanimation especially among underweight newborn. The indications of regional hospitalization must submit to the criteria which take into account not only, the human resources and technical equipment but also, the capacity of reception of the reference centers. A decentralized cooperation is expected to decongest higher level centers by giving all the possible opportunities to the newborn by a qualified support close to his birthplace.

In order to overcome these problems and to fight against maternal and neonatal mortality, the Ministry of Public Health in Morocco has developed a health sector strategy 2012-2016 whose main objectives are [1]:

- The promotion of safe motherhood: the update of delivery structures and a support circuit specialized in high-risk pregnancies, the medicalization of prenatal consultations, establishing custody for midwives, the strengthening of the humanization of maternity wards (air conditioners, heaters...), the acquisition of equipped ambulances and the creation of 20 new rural obstetric EMS (emergency medical service), the extension of free SONU (obstetric and emergency care neonatal) to support obstetric complications, the organization and reinforcement of the offer of neonatology care and creation of an intensive care unit for each region, the regionalization of the Moroccan health system is confirmed to be a strategic choice.

- Improvement of the reception conditions and the hospital care and development of specialized medical emergencies.

- Development of health in rural areas.

Reducing social disparities in access to health care remains a public health priority [23] [24] knowing that $11.5 \%$ of the population of Missour comes from towns with difficult access in winter period. However, it is essential to establish scores to detect especially unprotected women [25]. The identification of risk factors allows to settle specific prevention measures for each region [26].

The strengthening of medical and social support (permanence of access to health care, psychologist and social assistance...) of these women who are mostly housewives with low school attendance rates, the education of young women of child-bearing age and pregnancy monitoring should be priorities.

Networking with midwives will reduce the expenses of the public health and will surely allow the enlarge- 
ment of the public offer and promote the health and comfort of women in labor.

Midwives can visit women in labor in their own houses and collect information about the social and psychological situation and lodging conditions of the pregnant woman and provide her with assistance adapted to her needs possibly after a home birth. If necessary, Kangaroo care will contribute to the reduction of mortality and morbidity among premature infant and newborn with low birth weight.

Also, the World Health Organization emphasizes on the interest of community mobilization for the health of both mothers and newborn through cycles of learning and participatory actions with women's associations which aim for creating a space for discussion where women can raise priority issues and propose solutions adapted to the local constraints. However, the political support at national and local levels is essential. These associations must also collaborate with not only the health sector but also outside of it, such as road maintenance for the implementation of their interventions [27].

\section{Limitation of the Study}

The retrospective study proved interesting but difficult mainly because of the lack of data concerning certain Sociodemographic and epidemiological characteristics of pregnant women including marital status, work, medical coverage, school level, father's age, school level of the father, father's work.... Now these data are essential to understand the influence of different factoring and establish some correlations. Also, the small sample size complicated newborns is causing a lack of power of the study.

\section{Conclusion}

Supporting woman in precarious situation is a worrying problem facing the increasing needs. It is necessary to stress the vital role of community mobilization enabling vulnerable women in precarious social situation, designate priority issues and advocate local solutions to better prevent obstetric pregnancy complications as infection and neonatal suffering. "Kangaroo mother care" method could contribute to the wellbeing of premature infant with low birth primarily in settings where access to health services is difficult.

\section{Acknowledgements}

We thank all participants for taking part in this study.

\section{Competing Interests}

The authors declare that they have no competing interests.

\section{References}

[1] Stratégie sectorielle 2012-2016 du ministère de la santé au Maroc. http://www.sante.gov.ma/Docs/Documents/secteur\%20sant\%C3\%A9.pdf

[2] Koum, D.K., Exhenry, C., Penda, C.I., Nzima Nzima, V. and Pfisterf, R.E. (2014) Morbidité et mortalité néonatale dans un hôpital de district urbain à ressources limitées à Douala, Cameroun. Archives de Pédiatrie, 21, 147-156. http://dx.doi.org/10.1016/j.arcped.2013.11.014

[3] Wilson, N.W., Couper, I.D., De Vries, E., Reid, S., Fish, T., et al. (2009) A Critical Review of Interventions to Redress the Inequitable Distribution of Healthcare Professionals to Rural and Remote Areas. Rural and Remote Health, 9, 1060 .

[4] OMS (2015) Recommandations nationales de bonnes pratiques. Ministère de la santé Rabat Maroc.

[5] Ouédraogo/Yugbaré, S.O., Kaboré, R., et al. (2013) Facteurs de risque de décès des nouveau-nés de faible poids de naissance à Ouagadougou. Journal de pédiatrie et de puériculture, 26, 204-209. http://dx.doi.org/10.1016/j.jpp.2013.03.002

[6] Jost, C., Mariani-Kurkdjian, P., Biran, V., Boissinot, C. and Bonacorsia, S. (2015) Intérêt des prélèvements périnataux dans la prise en charge des nouveau-nés suspects d’infections bactériennes précoces. Revue francophone des laboratoires, 47, 1837-1841. http://dx.doi.org/10.1016/s1773-035x(15)30032-0

[7] Cottineau, M., Launay, E., Branger, B., Caillon, J., Mullere, J.-B., Boscher, C., Laurens, C., Cabaret, B., Roze, J.-C. and Gras-Le Guen, C. (2014) Valeur diagnostique des critères de suspicion d’infection néonatale précoce: Bilan dix ans. Archives de Pédiatrie, 21, 187-193. http://dx.doi.org/10.1016/j.arcped.2013.11.011 
[8] Verani, Jr, McGee, L. and Schrag, S.J. (2010) Prevention of Perinatal Group B Streptococcal Disease-Revised Guidelines from CDC 2010. Recommendations and Reports, 59, 1-32.

[9] Bernard, P. (1993) L’immigration. Le monde eds. Hachette, Marabout, Paris.

[10] Zeitlin, J., Combier, E., De Caunes, F. and Papiemik, E. (1998) Social Demographic Risk Factors for Perinatal Mortality. A Study for Perinatal Mortality in French District of Seine-Saint-Denis. Acta Obstetricia et Gynecologica Scandinavica, 77, 826-835. http://dx.doi.org/10.1080/j.1600-0412.1998.770808.x

[11] You, D., Jones, G. and Wardlaw, T. (2011) Levels \& Trends in Child Mortality: Report 2011. An Inter-Agency Group for Child Mortality, New York.

[12] Lawn, J.E., Kerber, K., Enweronu-Laryea, C. and Cousens, S. (2010) 3.6 Million Neonatal Deaths-What Is Progressing and What Is Not? Seminars in Perinatology, 34, 371-386. http://dx.doi.org/10.1053/j.semperi.2010.09.011

[13] Lawn, I., Cousens, S. and Zupan, J. (2005) 4 Million Neonatal Deaths: When? Where? Why? Lancet, 65, 891-900. http://dx.doi.org/10.1016/S0140-6736(05)71048-5

[14] Lecomte, T., Mizrahi, A. and Mizrahi, A. (1996) Précarité sociale: Cumul des risques sociaux et médicaux. Enquête sur la santé et les soins médicaux en France. CREDES, Paris.

[15] Gayral-Taminh, M., Daubisse-Marliac, L., Baron, M., Maurel, G., Rème, J-M. and Grandjean, H. (2005) Caractéristiques socio-démographiques et risques périnatals des mères en situation de précarité. Journal de Gynécologie Obstétrique et Biologie de la Reproduction, 34, 23-32. http://dx.doi.org/10.1016/S0368-2315(05)82667-5

[16] Berkowitz, G.S. and Papiernik, E. (1993) Epidemiology of Preterm Birth. Epidemiologic Reviews, 15, 414-441.

[17] Vocation Sage Femme (2008) Femmes enceintes en situation de grande précarité, quelle prise en charge? No. 66.

[18] Garabedian, C., Sfeir, R., Langlois, C., Bonnard, A., Khen-Dunlop, N., et al. (2015) Le diagnostic anténatal modifie-til la prise en charge néonatale et le devenir à 1 an des enfants suivis pour atrésie de l'œsophage de type III? Journal de Gynécologie Obstétrique et Biologie de la Reproduction, 44, 848-854. http://dx.doi.org/10.1016/j.jgyn.2014.12.004

[19] Sabiri, N., Kabiri, M., Razine, R., Kharbach, A., Berrada, R. and Barkat, A. (2013) Facteurs de risque des malformations congénitales: Etude prospective à la maternité Souissi de Rabat au Maroc. Journal de Pédiatrie et de Puériculture, 26, 198-203. http://dx.doi.org/10.1016/j.jpp.2013.05.001

[20] Rouget, F., Monfort, C., Bahuau, M., Nelva, A., Herman, C., Francannet, C., Robert-Gnansia, E. and Cordier, S. (2005) Folates en période peri-conceptionnelle et prévention du risque de fente orofaciale: Rôle des apports alimentaires en France. Revue d'Épidémiologie et de Santé Publique, 53, 351-360. http://dx.doi.org/10.1016/S0398-7620(05)84617-6

[21] Afssa (2003) Enrichissement de la farine en vitamines B en France: Proposition d’un programme-pilote. Agence française de sécurité sanitaire des aliments.

[22] Flamant, C. and Gascoin, G. (2013) Devenir précoce et prise en charge néonatale du nouveau-né petit pour l'âge gestationnel. Journal de Gynécologie Obstétrique et Biologie de la Reproduction, 42, 985-995. http://dx.doi.org/10.1016/j.jgyn.2013.09.020

[23] Bagou, G. (2009) Régulation des transferts in utéro et réseau de transfert périnatal. 51 Congrès national d'anesthésie et de réanimation. Médecins. Urgences vitales. (C) Elsevier Masson SAS.

[24] Leclerc, A., Fassin, D., Grandjean, H., Kaminski, M. and Lang, T. (2000) Les inégalités sociales de santé. La découverte-INSERM, Paris.

[25] Convers, M. (2010) Utilisation du score Epice pour repérer la précarité et optimiser la prise en charge de la grossesse. La Revue Sage-Femme, 9, 3-9. http://dx.doi.org/10.1016/j.sagf.2009.12.003

[26] Convers, M., Langeron, A., Sass, C., Moulin, J.-J., Augier, A., Varlet, M.-N., Seffert, P. and Chêne, G. (2012) Intérêt de l'échelle d'évaluation de la précarité EPICES en obstétrique. Is the socioeconomic de privation EPICES score useful in obstetrics? Chêne. Gynécologie Obstétrique \& Fertilité, 40, 208-212. http://dx.doi.org/10.1016/j.gyobfe.2011.10.014

[27] OMS (2014) Recommandations de l’OMS relative à la mobilisation communautaire pour la santé de la mère et du nouveau-né au moyen de cycles d'apprentissage et d'actions participatifs avec les associations féminines sous la conduite d'animateurs. www.who.int 